\title{
Prolonged increase in digital blood flow following Iloprost infusion in patients with systemic sclerosis
}

\author{
M. Rademaker, R.H.M. Thomas, G. Provost, J.A. Beacham, ${ }^{1}$ E.D. Cooke ${ }^{1}$ \\ and J.D. Kirby
}

Departments of Dermatology and 'Medical Electronics, St Bartholomew's Hospital, West Smithfield, London ECIA $7 B E, U K$.

\begin{abstract}
Summary: Thirteen patients with Raynaud's phenomenon secondary to systemic sclerosis received three 8-hour infusions of a synthetic prostacyclin analogue (Iloprost) on consecutive days and were followed-up over a period of 10 weeks during the winter of $1985 / 86$. Six weeks after infusion, digital peripheral vascular resistance had fallen $(P<0.05)$ and dicrotic notch proportion of pulse amplitude increased $(P<0.05)$. Digital blood flow and pulse amplitude (measured by photoplethymography) were also increased but did not reach statistical significance. The trend of improvement in these blood flow parameters was still evident after 10 weeks.

The number of cutaneous lesions (digital ulcers, etc) fell from 26 lesions before infusion to only 7 lesions by the end of the study, confirming the subjective improvement reported by the patients.
\end{abstract}

\section{Introduction}

The anti-platelet aggregation and peripheral vasodilatory properties of prostaglandins $\left(\mathrm{PGF}_{2}\right.$ and $\mathrm{PGI}_{2}$ ) and their analogues have been well documented in healthy volunteers, ${ }^{1,2}$ patients with Raynaud's syndrome $^{3,4}$ and patients with peripheral vascular disease. ${ }^{5}$ While the anti-platelet and other rheological effects appear to be of short duration, a number of investigators have suggested that the beneficial effects, as measured by a reduction in the frequency and severity of Raynaud's attacks, may persist for several weeks following intravenous infusions. ${ }^{6,7}$ The purpose of this investigation was to examine the duration of effect of Iloprost, a chemically stable carbacyclin derivative of prostacyclin, on the peripheral vasculature in patients with systemic sclerosis.

\section{Methods}

\section{Patients}

With the approval of the St Bartholomew's Hospital Ethical Committee, 13 patients (12 women, age $49 \pm 3$ years, range 22-64 years) with the clinical, serological and capillaroscopic features of systemic sclerosis were studied. All fulfilled the American Rheumatism

Correspondence: M. Rademaker B.M., M.R.C.P. Accepted: 18 February 1987
Association criteria for systemic sclerosis and had severe Raynaud's phenomenon for $16 \pm 4$ years, range 5-50 years.

Patients gave informed consent and were admitted to the trial. All vaso-active drugs, such as slow channel calcium antagonists, and all drugs with anti-platelet activity, such as non-steroidal anti-inflammatory agents, were discontinued for at least 2 weeks before admission into the study. Patients with abnormal haemostasis, diabetes mellitus and hyperviscosity syndrome were excluded. The study was undertaken during the winter months of $1985 / 86$.

\section{The study}

Iloprost was infused at a rate of $2 \mathrm{ng} / \mathrm{kg} / \mathrm{min}$ via a peripheral vein, 8 hours daily, on 3 consecutive days.

Patients were asked to complete a daily diary card recording the number and severity of Raynaud's attacks and whether they believed that their hands were generally warmer or colder than they would have expected considering the outdoor temperature. The patients were examined one week prior to and then 2,6 and 10 weeks after the infusion of Iloprost. Assessment included recording of any digital lesions (digital ulcers or fissures), full blood count, liver function tests, urea and electrolytes. Patients were also asked, at each outpatient review, whether they felt they were much improved, improved, no different, worse, or much worse following the infusion. 


\section{Blood flow assessment}

Measurement of the peripheral blood flow in the forearm and digits was performed in a temperature and humidity controlled laboratory $\left(24 \pm 1^{\circ} \mathrm{C} ; 40\right.$ $60 \%$ humidity) with the patient seated, lightly clad, and with the exposed arms supported on a frame, the hands being held at heart level. Equilibration of hand temperature with the ambient temperature was assured using infra-red thermography (AGA Medical $680)$ to measure mean hand temperature. When a steady state temperature was achieved (this usually required 10-15 minutes) strain-gauge venous occlusion plethysmography (SPG) (Medasonics Model SPG-16) was used to determine blood flow in the forearm and index finger using SG-24 and SG-6 type gallium-indium strain gauges respectively. Microcirculatory flow in the pulp of the middle fingers was measured simultaneously using the AC output of a two channel photoplethysmograph (PPG) (Medasonics Model PA13).

These recordings, along with a simultaneous ECG (lead II), were continuously displayed on a chart recorder and digitised by an A-D converter of a microcomputer (Nova 3) at a sampling rate of $256 \mathrm{~Hz}$ and stored on magnetic tape for subsequent analysis. The method has been described fully previously. ${ }^{8}$

The computer programme analysed the SPG data to provide a figure for mean blood flow $(\mathrm{ml} / 100 \mathrm{ml}$ tissue/min) and averaged the PPG complexes occurring during a 30 second period of time each minute, avoiding data obtained during SPG cuff compression (6 seconds) and 20 seconds thereafter. Vertical PPG parameters, e.g. amplitude, were derived from a standard deflection and horizontal parameters were timed (in milliseconds) from the $R$-wave of the simultaneous ECG complex. Immediately after the blood flow measurements, blood pressure (mean of three recordings) was recorded with the patient sitting in the same position using a Hawksley random zero sphygmomanometer. Peripheral vascular resistance (PVR) in the forearm and finger was calculated by dividing the mean blood pressure by blood flow.

\section{Statistical analysis}

All the results are expressed as mean \pm standard error of the mean. Statistical analysis was performed using Student's two-tailed paired $t$ test.

\section{Results}

\section{Clinical}

Compliance with the completion of the daily diary was incomplete in some patients such that an attempt at analysis was considered inappropriate. Patients repor- ted subjective improvement in 9 cases $(5$ much better, 4 better). Three patients felt they had not benefitted from the infusion. Only one patient thought she was probably worse as a result of the infusion when asked at the 10 week follow-up (although she thought she had improved at the 2 and 6 week follow-ups).

The number of cutaneous lesions fell markedly from 26 lesions present at the start of the trial, to 14 lesions two weeks after infusion and only 7 lesions at the end of the study. There was no significant change in the full blood count or blood chemistry.

\section{Blood flow}

Digital peripheral vascular resistance (Figure 1) was significantly reduced $(P<0.05)$ and dicrotic notch proportion of amplitude (DN-P) (Figure 2) increased $(P<0.05)$ at 6 weeks but not at 10 weeks though the trend was maintained. Digital PVR was reduced in 8 of the 13 patients $(62 \%) 2$ weeks after infusion, in 9

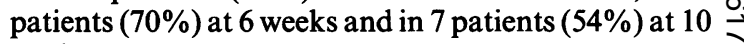
weeks.

Digital blood flow (Figure 3) was increased at 6 and 10 weeks and PPG amplitude was increased (Figure 4) at 6 weeks after the infusion of Iloprost although neither reached statistical significance.

During the study period, there was no significant change in resting blood pressure $(123 \pm 4 / 73 \pm 38 \%$ forearm blood flow or forearm peripheral vascular. resistance.

\section{Discussion}

This study has shown that the increase in digital blood flow following an infusion of Iloprost given for 8 hours on three consecutive days, persists for many weeks, confirming previous reports that the beneficial effects of intravenous prostacyclins can still be detected long after cessation of therapy. ${ }^{2,3,6,7}$

The evidence of increased blood flow in this study was obtained by observing the healing of ischaemic skin lesions and by objective measurement of total digital (SPG) and microcirculatory flow (PPG) at 2, 63 and 10 weeks following infusion. The changes in blood $\mathrm{O}$ flow and the peripheral vascular resistance (PVR), showed a distinctive pattern: there was a gradual $\frac{7}{2}$ increase in flow and vessel compliance [as shown in dicrotic notch proportion of amplitude (DN-P)] and a $\widetilde{N}$ reduction in PVR at 2 weeks which became statis- $N$ tically significant at 6 weeks; whilst the values remained elevated above baseline at 10 weeks after $\omega$ infusion they were no longer statistically significant suggesting a fall-off towards the pre-treatment state of blood flow.

Whilst it has been shown that the immediate effect of an infusion of prostacyclin is generalized dilata- 


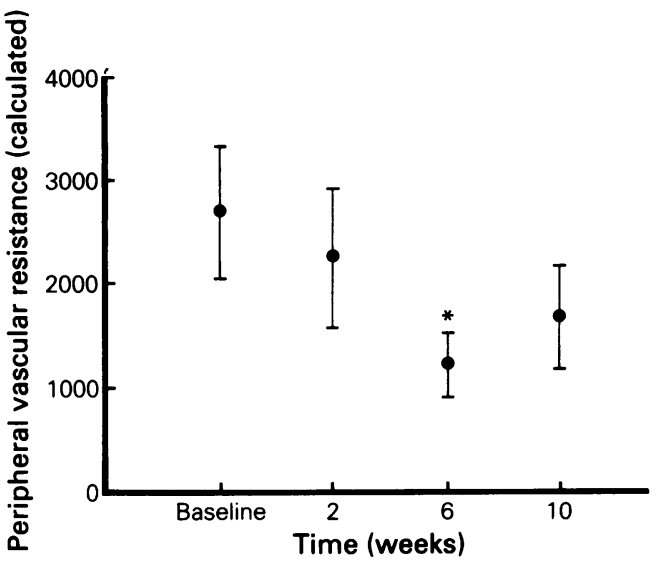

Figure 1 Digital peripheral vascular resistance (PVR) following infusion of Iloprost (mean \pm s.e.m.). $* P<0.05$.

tion, ${ }^{9}$ this effect passes off rapidly when the infusion is stopped and is unlikely to explain our findings. Similarly there is no evidence, at present, to suggest that a prostanoid effect on platelets ${ }^{3}$ would explain the pattern of continued improvement of digital blood flow over a number of weeks as observed in this investigation.

It is, however, recognised that a serum factor cytotoxic to endothelial cells exists in the blood of patients with systemic sclerosis. ${ }^{10,11}$ In consequence there is an increase in endothelial platelet deposition, with the release of a number of vasoactive amines including thromboxane (TXA ${ }_{2}$ ), a reduction in elaboration and release of vasodilatory substances

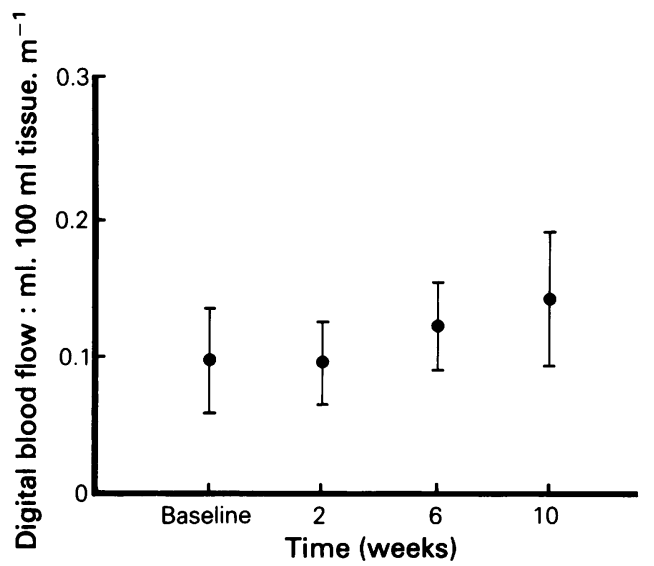

Figure 3 Digital blood flow following infusion of Iloprost (mean \pm s.e.m.).

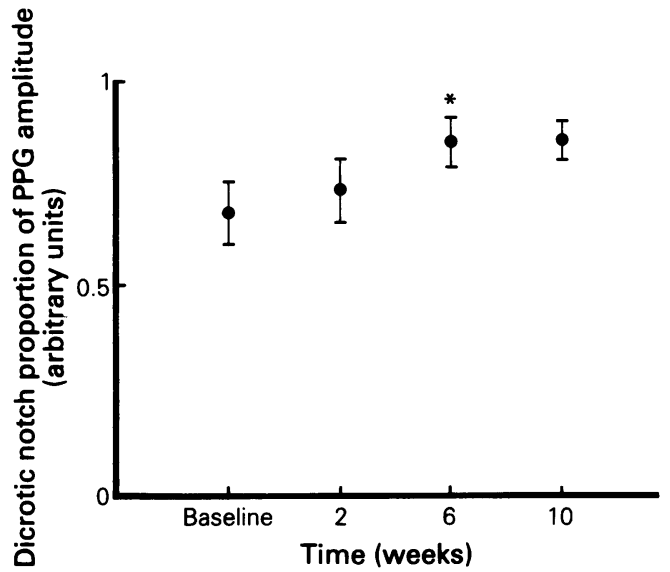

Figure 2 Dicrotic notch proportion of photoplethysmograph amplitude following infusion of Iloprost (mean \pm s.e.m.). ${ }^{*} P<0.05$.

such as prostacyclin (PG12), and possibly endothelium-derived relaxing factor (EDRF). ${ }^{12}$

Although the explanation for the prolonged increase in blood flow following a short infusion of Iloprost remains to be elucidated, it is possible to speculate that the drug may protect endothelium and facilitate endothelial repair, thereby breaking the vicious cycle of endothelial damage and altered blood flow.

\section{Acknowledgement}

We are grateful to Sharing Health Care Ltd. for supplying Iloprost.

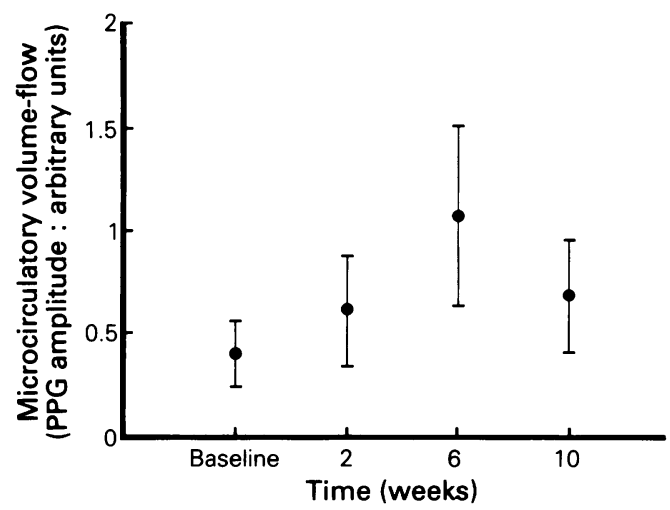

Figure 4 Microcirculatory volume-flow (PPG amplitude: AC output) following infusion of Iloprost (mean \pm s.e.m.). 


\section{References}

1. Cowley, A.J., Heptinstall, S. \& Hampton, J.R. Effects of prostacyclin and of the stable prostacyclin analogue ZK 36374 on forearm blood flow and blood platelet behaviour in man. Thromb Haemost 1985, 53: 90-94.

2. Cooke, E.D., Bowcock, S.A., Watkins, C.J., Rustin, M.H. \& Kirby, J.D. CL 115 347, an analogue of prostaglandin $\mathrm{E}_{2}$. Peripheral circulatory effects of single ascending doses administered transdermally in normal subjects and patients with Raynaud's phenomenon. Angiology 1985, 36: 867-871.

3. Belch, J.F., Newman, P., Drury, J.K. et al. Intermittent epoprostenol (prostacyclin) infusion in patients with Raynaud's syndrome. A double-blind controlled trial. Lancet 1983, i: 313-315.

4. Dunger, D.B., Dillon, M.J., Daman-Williams, C., Cooke, E.D. \& Bowcock, S.A. Treatment of childhood Raynaud's disease with transdermal prostaglandin $\mathrm{E}_{2}$ analogue. Lancet 1985 , ii: 50.

5. Belch, J.F., McArdle, B., Pollock, J.G. et al. Epoprostenol (prostacyclin) and severe arterial disease. A double blind trial. Lancet 1983, i: 315-317.

6. Kyle, V., Parr, G., Salisbury, R., Page Thomas, P. \&
Hazleman, B. Prostaglandin $\mathrm{E}_{1}$ vasospastic disease and thermography. Ann Rheum Dis 1985, 44: 73-78.

7. Dowd, P.M., Martin, M.F., Cooke, E.D. et al. Treatment of Raynaud's phenomenon by intravenous infusion of prostacyclin. Br J Dermatol 1982, 106: 81-89.

8. Cooke, E.D., Bowcock, S.A. \& Smith, A.T. Photoplethysmography of the distal pulp in the assessment of the vasospastic hand. Angiology 1985, 36: 33-40.

9. Schillinger, E., Krias, T., Lehman, M. \& Stock, G. Iloprost. In Scriabine, A. (ed) Nèw Cardiovascular Drugs. Raven Press, New York, 1986, pp 209-231.

10. Meyer, O., Haim, T., Dryll, A., Lansaman, J. \& Ryckewaert, A. Vascular endothelial cell injury in progressive $\vec{\omega}$ systemic sclerosis and other connective tissue diseases. Clin Exp Rheumatol 1983, 1: 29-34.

11. Kahaleh, M.B., Sherer, G.K. \& Leroy, E.C. Endothelial injury in scleroderma. J Exp Med 1979, 149: 1326-1335. के

12. Gryglewski, R.J., Moncada, S. \& Palmer, R.M. Bioassay of prostacyclin and endothelium-derived relaxing factor $P$ (EDRF) from porcine aortic endothelial cells. $\mathrm{Br} J$ Pharmacol 1986, 87: 685-694. 